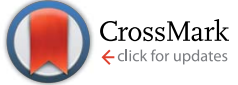

Cite this: RSC Adv., 2017, 7, 1887
Received 14th October 2016 Accepted 4th December 2016

DOI: $10.1039 / c 6 r a 25238 a$

www.rsc.org/advances

\section{Influence of electronic structure on visible light photocatalytic activity of nitrogen-doped $\mathrm{TiO}_{2} \dagger$}

\begin{abstract}
Daigo Kusano, Masato Emori and Hiroshi Sakama*
Nitrogen (N)-doped $\mathrm{TiO}_{2}$ thin films were synthesized by sol-gel methods from precursor solutions with or without urea and post calcination in $\mathrm{NH}_{3}$ gas. Their structural and electronic properties were characterized by $\mathrm{X}$-ray diffraction and $\mathrm{X}$-ray photoelectron spectroscopy utilizing synchrotron radiation. $\mathrm{N}$-doped $\mathrm{TiO}_{2}$ powders were synthesized for the estimation of visible light photocatalytic activities. $\mathrm{N}$-doped $\mathrm{TiO}_{2}$ thin films revealed polycrystalline anatase phases. $\mathrm{N}$ was chiefly doped into substitutional sites. The densities of $\mathrm{N}$ and defects (oxygen vacancies and reduced $\mathrm{Ti}$ species) increased with elevating calcination temperature. Localized states associated with doped $\mathrm{N}$ were successfully found from shoulder structures of valence band spectra, which were located at $0.24 \mathrm{eV}$ to $0.34 \mathrm{eV}$ above the valence band maximum in the band gap. Incorporated $\mathrm{N}$ enhanced the photocatalytic activity, whereas defects reduced it. The highest photocatalytic activity was obtained by synthesizing $\mathrm{N}$-doped $\mathrm{TiO}_{2}$ powders from a precursor solution with urea and subsequent calcination at $550{ }^{\circ} \mathrm{C}$ due to high-density $\mathrm{N}$ and low-density defects. Consequently, the optimum N/O atomic ratio was shown to be approximately 0.06 . It became possible to achieve heavier $\mathrm{N}$ doping and better photocatalytic activity under vis light irradiation using urea than any other study only using $\mathrm{NH}_{3}$ gas for nitridation.
\end{abstract}

\section{Introduction}

Semiconductor photocatalysis is one of the most effective methods for chemical utilization of solar energies. Of all photocatalytic materials, $\mathrm{TiO}_{2}$ is the most promising because of its photoactivity, nontoxicity to environments and low cost of fabrication. ${ }^{1-3}$ However, the optical response of $\mathrm{TiO}_{2}$ is limited to ultraviolet (UV) light because of its wide band gap (3.0 eV for rutile and $3.2 \mathrm{eV}$ for anatase). For more efficient use of solar energies in photocatalytic reactions, it is necessary to extend the optical response of $\mathrm{TiO}_{2}$ to the visible (vis) light region. ${ }^{4}$ Thus, the fabrication of nitrogen $(\mathrm{N})$-doped $\mathrm{TiO}_{2}$ with vis light activity has been considered as a promising approach because the N2p derived states are generated just above the valence band (VB) in the band gap.,

$\mathrm{N}$ atoms are known to be incorporated into interstitial and/or substitutional sites (replacement of $\mathrm{O}$ ) in $\mathrm{TiO}_{2}$ lattices. The interstitial nitrogen $\left(\mathrm{N}_{\mathrm{i}}\right)$ and substitutional nitrogen $\left(\mathrm{N}_{\mathrm{s}}\right)$ are supposed to have different influences on the electronic states as well as vis light activities. Some authors have reported that $\mathrm{N}_{\mathrm{s}}$ contributes the generation of $\mathrm{N}$-derived states and facilitates vis light photocatalysis, ${ }^{3,5,7-9}$ whereas others have claimed that photoactive nitrogen is not $\mathrm{N}_{\mathrm{s}}$ but just $\mathrm{N}_{\mathrm{i}} \cdot{ }^{\mathbf{1 0 - 1 3}}$ Very

Department of Physics, Sophia University, Kioi-cho, Chiyoda-ku, Tokyo 102-8554, Japan.E-mail: h-sakama@sophia.ac.jp

$\dagger$ Electronic supplementary information (ESI) available. See DOI: 10.1039/c6ra25238a recently, DFT (density functional theory) calculation has shown that $\mathrm{N}$ prefers to replace $\mathrm{Ti}$ (Ti-vacancy-site: $\mathrm{N}_{\mathrm{Ti}}$ ) rather than $\mathrm{O}$ to form $\mathrm{NO}_{x} \cdot{ }^{14}$ Furthermore, oxygen vacancies $\left(\mathrm{V}_{\mathrm{O}}\right)$ near surface regions act as recombination centers and depress photocatalytic activities. In general, photocatalytic activities under vis light have been discussed using UV-vis optical absorption experiments. However, defect states originated from oxygen vacancies and reduced $\mathrm{Ti}$ species $\left(\mathrm{Ti}^{3+}, \mathrm{Ti}^{2+}\right)$ in the band gap as well as N-derived states were shown to contribute to light absorption characteristics of $\mathrm{N}-\mathrm{TiO}_{2}$ in vis light region, which makes the situations more complicated. In reality, defect states due to $\mathrm{V}_{\mathrm{O}}$ located at 2.02 to $2.45 \mathrm{eV}$ above VBM were chiefly responsible for absorption of vis light with wavelength shorter than $614 \mathrm{~nm} .{ }^{15}$ Therefore, in spite of intensive theoretical and experimental studies on $\mathrm{N}-\mathrm{TiO}_{2}$, primary issues such as the origin of vis light photocatalytic activities and the effect of chemical and electronic states of constituent elements ( $\mathrm{Ti}, \mathrm{O}, \mathrm{N}$ ) and defects on photocatalytic activities are still under debate. One of the most suitable techniques for direct observation of occupied N-derived states is X-ray photoelectron spectroscopy (XPS) since N-derived states are easily distinguished from defect states in terms of binding energy $\left(E_{\text {bin }}\right)$ of photoelectrons. Nevertheless, few works have been carried out so far to observe $\mathrm{N}$-derived states in the band gap using XPS with excellent $\mathrm{S} / \mathrm{N}$ (signal to noise) ratio.

In the present study, $\mathrm{N}-\mathrm{TiO}_{2}$ thin films were synthesized on $\mathrm{Si}(100)$ using the combination of sol-gel method and nitridation in $\mathrm{NH}_{3}$ gas. This combination is one of the most widely-used and 
reproducible methods to synthesize $\mathrm{N}-\mathrm{TiO}_{2}$ photocatalysts. ${ }^{\mathbf{1 0 , 1 2 , 1 3}}$ The crystalline structures were investigated by X-ray diffraction (XRD) and electronic structures were examined by XPS utilizing synchrotron radiation. Synchrotron radiation is best suited as a X-ray source for XPS measurements on $\mathrm{N}-\mathrm{TiO}_{2}$ with high $\mathrm{S} / \mathrm{N}$ ratios owing to its high intensity. Photocatalytic activities of $\mathrm{N}-\mathrm{TiO}_{2}$ powders prepared by sol-gel methods using urea $\left(\left(\mathrm{NH}_{2}\right)_{2} \mathrm{CO}\right)$ as a $\mathrm{N}$ source were shown to be higher than those using $\mathrm{NH}_{3}$ solution. ${ }^{16}$ Therefore, $\mathrm{N}-\mathrm{TiO}_{2}$ powders were synthesized by nitridation in $\mathrm{NH}_{3}$ gas with or without urea for estimation of photocatalytic activities under vis light irradiation. Then, $\mathrm{N}$ species active for vis light, energy levels of $\mathrm{N}$-derived states in the band gap, the optimum density of $\mathrm{N}$ and the influence of defects on photocatalytic activities are discussed based on XRD and XPS results.

\section{Experimental}

$\mathrm{N}-\mathrm{TiO}_{2}$ thin films were synthesized on $\mathrm{Si}(100)$ substrates by two kinds of sol-gel methods for characterization of $\mathrm{N}-\mathrm{TiO}_{2}$.

In method $\mathrm{A}$, precursor solutions were prepared from a mixture of titanium tetra- $n$-butoxide monomer and 2-methoxyethanol. The solution was deposited on $\mathrm{Si}(100)$ surfaces using a syringe and the samples were rotated at $3000 \mathrm{rpm}$ for 50 seconds using a spin-coater, followed by post gelation at $150{ }^{\circ} \mathrm{C}$ for 60 seconds. The samples were subsequently calcined in $\mathrm{NH}_{3}$ gas for 3 hours at $450{ }^{\circ} \mathrm{C}, 500{ }^{\circ} \mathrm{C}, 550{ }^{\circ} \mathrm{C}$ or $600{ }^{\circ} \mathrm{C}$ for $\mathrm{N}$ doping or in the air to produce pure $\mathrm{TiO}_{2}$ films for a comparison. The $\mathrm{N}-\mathrm{TiO}_{2}$ thin films were called A-450, A-500, A-550 and A-600, respectively.

In method B, urea powders were added to sol-gel precursor solutions with controlling nitrogen dosage at 3, 6, 20 or 40 at $\%$ by changing the amount of urea powders and calcination temperature in $\mathrm{NH}_{3}$ flow at $450{ }^{\circ} \mathrm{C}, 500{ }^{\circ} \mathrm{C}$ or $550{ }^{\circ} \mathrm{C}$. Urea is known as a reductant of $\mathrm{NO}_{x}$ from combustors such as diesel engines and boilers. It has an ability to produce $\mathrm{V}_{\mathrm{O}}$ in $\mathrm{TiO}_{2}$ lattices and simultaneously act as a $\mathrm{N}$ source. The subsequent processes were similar to method A. The synthesized films with dosage of $x$ at $\% \mathrm{~N}$ followed by calcination in $\mathrm{NH}_{3}$ flow at $450{ }^{\circ} \mathrm{C}$, $500{ }^{\circ} \mathrm{C}$ and $550{ }^{\circ} \mathrm{C}$ are called $\mathrm{Bx}-450, \mathrm{Bx}-500$ and $\mathrm{Bx}-550$, respectively.

XRD patterns of the films were analyzed by X-ray diffraction with $\mathrm{Cu}$ K $\alpha$ radiation (NEW D8 ADVANCE, Bruker AXS). The XPS measurements were performed utilizing synchrotron radiation at Beam Line (BL)-3B and -13A of Photon Factory (PF) in high energy accelerator research organization (KEK). The measurements were carried out at room temperature in ultrahigh vacuum chamber with base pressure of $2.0 \times 10^{-8} \mathrm{~Pa}$ at both BLs. The samples were fixed on a Ta holder. Prior to XPS measurements, in situ treatment to remove surface contaminations included mild $\mathrm{Ar}^{+}$sputtering $(2 \mathrm{kV}, 1.0 \mu \mathrm{A})$ and annealing at $900{ }^{\circ} \mathrm{C}$ in vacuum. At BL-3B, a hemispherical electron energy analyzer (HA45, VSW) was used to acquire the spectra with the typical overall energy resolution of $200 \mathrm{meV}$ at the photon energy of $60 \mathrm{eV}$. For the core-level XPS measurements at BL-13A, a Gamma Date/Scienta SES200 electron-energy analyser was used. The typical overall energy resolution of the spectra was $170 \mathrm{meV}$ at the photon energy of $600 \mathrm{eV}$. The binding energy of XPS spectra was referenced to Fermi level, which was determined from Fermi cutoff in the spectra of Ta sample holder. $\mathrm{N} / \mathrm{O}$ atomic ratios of films were deduced from XPS N1s and O1s peaks. ${ }^{32}$

Photocatalytic activities of $\mathrm{N}-\mathrm{TiO}_{2}$ were evaluated by degradation of methylene blue $(\mathrm{MB})$ under vis light $\left(1.5 \times 10^{4} \mathrm{~lx}\right)$ from a $180 \mathrm{~W}$ metal halide lamp. Although the change in the total organic carbon concentration (TOC), the chemical oxygen demand (COD), or the biochemical oxygen demand (BOD) in the dye solution by light irradiation should be measured for overall evaluation of photocatalytic activities, ${ }^{18}$ this simple method using MB has also been recognized as a standard one in case of $\mathrm{TiO}_{2}$ photocatalysts. ${ }^{19}$ In the experiments of photocatalytic degradation of $\mathrm{MB}, \mathrm{N}-\mathrm{TiO}_{2}$ powders were utilized in place of $\mathrm{N}-\mathrm{TiO}_{2}$ thin films because $\mathrm{N}-\mathrm{TiO}_{2}$ thin films had too small surface areas to degrade MB substantially during irradiation time. Hence, $\mathrm{N}-\mathrm{TiO}_{2}$ powders were synthesized by two kinds of procedures for estimation of photocatalytic activities under vis light irradiation. In the first procedure, pure anatase $\mathrm{TiO}_{2}$ powders were nitrided in $\mathrm{NH}_{3}$ gas flow for 3 hours at $450{ }^{\circ} \mathrm{C}, 500{ }^{\circ} \mathrm{C}, 550{ }^{\circ} \mathrm{C}$ or $600{ }^{\circ} \mathrm{C}$, respectively, analogous to method $\mathrm{A}$. In an alternative procedure analogous to method $\mathrm{B}$, urea powders with different ratios of $3,6,10,20$, or 40 at\% $\mathrm{N}$ were added prior to nitridation in $\mathrm{NH}_{3}$ gas at the temperatures similar to the first procedure. A fixed amount of $\mathrm{N}-\mathrm{TiO}_{2}$ powders $(0.06 \mathrm{~g})$ were added into $100 \mathrm{ml}$ of $\mathrm{MB}$ aqueous solution $\left(10 \mu \mathrm{mol} \mathrm{l}^{-1}\right)$. However, since there is a possibility of direct photolytic degradation of MB by irradiation of vis light with wavelength $\lambda$ around $665 \mathrm{~nm}$ (peak maximum in absorption spectra), a low-pass optical filter with cutoff wavelength of $500 \mathrm{~nm}$ was inserted between lamp and solution. In addition, another high-pass optical filter with cutoff wavelength of $420 \mathrm{~nm}$ was used for elimination of UV light. Accordingly, direct photolytic degradation of $\mathrm{MB}$ under vis light irradiation was found to be negligible in comparison with photocatalytic degradation.

\section{Results and discussion}

\subsection{X-ray diffraction patterns}

XRD patterns of the samples grown by method A are shown in Fig. 1(a). Several Bragg reflections of anatase phase are identified, demonstrating that the polycrystalline anatase was obtained by method A. The crystallinity of the films deduced from full width at the half maximum (FWHM) of anatase (101) peak improved with the increase in the calcination temperature. The crystal size $D$ of each film is also indicated in Fig. 1. It was calculated from Scherrer's equation

$$
D=0.94 \lambda / \beta \cos \theta
$$

where $D$ is the crystal size, $\lambda$ is the wavelength of $\mathrm{X}$-ray radiation, $\beta$ is FWHM of anatase (101) peak, and $\theta$ is the diffraction angle. ${ }^{20}$

As shown in Fig. 1(b), XRD patterns of the films synthesized by method $\mathrm{B}$ also revealed the polycrystalline anatase phase. 

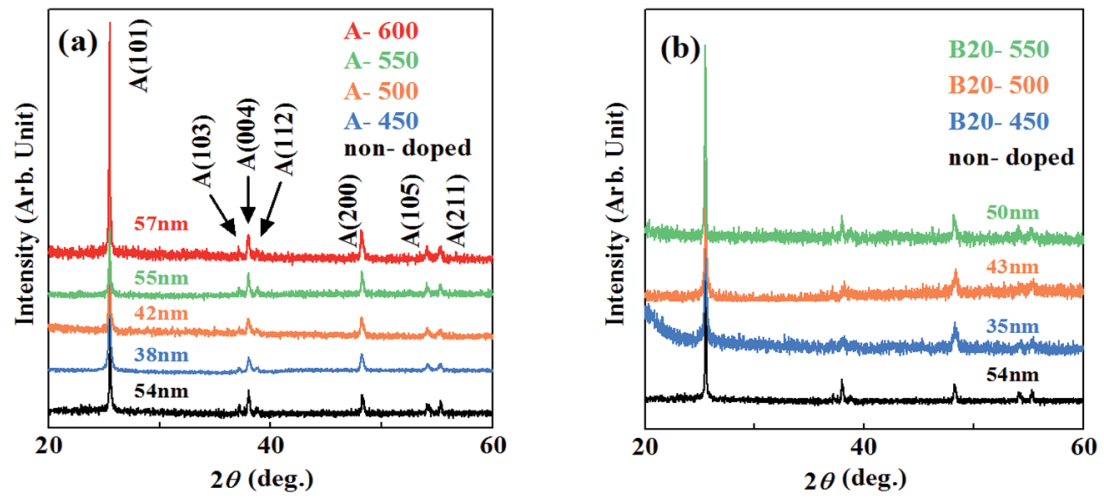

Fig. 1 XRD patterns of the samples grown by (a) method $A$ and (b) $B$.

The crystal sizes were almost similar, indicating that incorporation of $\mathrm{N}$ hardly degrades the crystallinity of the films grown at these temperatures.

\subsection{Core-level XPS spectra}

Fig. 2 shows the N1s, Ti2p core-level XPS spectra for the samples synthesized by method A. In Fig. 2(a), there appear no peaks in N1s spectra for the samples grown below $500{ }^{\circ} \mathrm{C}$, while peaks appear at around $E_{\text {bin }}=397 \mathrm{eV}$ with a small peak at around $E_{\text {bin }}$ $=400 \mathrm{eV}(\mathrm{A}-600)$ for the samples grown above $550^{\circ} \mathrm{C}$. For more quantitative understanding of chemical states of $\mathrm{N}$, each N1s spectrum was decomposed into components by least-square fitting using Gaussian functions. ${ }^{21}$ In the fitting procedures, linear functions were assumed for background of spectra. Though two Gaussian functions were used for first fitting, it resulted in failure to reproduce the background-subtracted spectra. Hence, another Gaussian function was added to them. Consequently, all N1s spectra were successfully decomposed into three Gaussian components $\left(\alpha_{1}, \alpha_{2}\right.$ and $\left.\alpha_{3}\right)$ with $E_{\text {bin }}$ $\approx 397 \mathrm{eV}, 398 \mathrm{eV}$ and $400 \mathrm{eV}$, respectively. One example of them is shown in Fig. 2(b) for A-600. Thus, $\mathrm{N}$ species in different chemical environments coexist. $\mathrm{N} 1 \mathrm{~s}$ spectra for $\mathrm{N}-\mathrm{TiO}_{2}$ have been reported by many authors. Asahi et al. has reported that
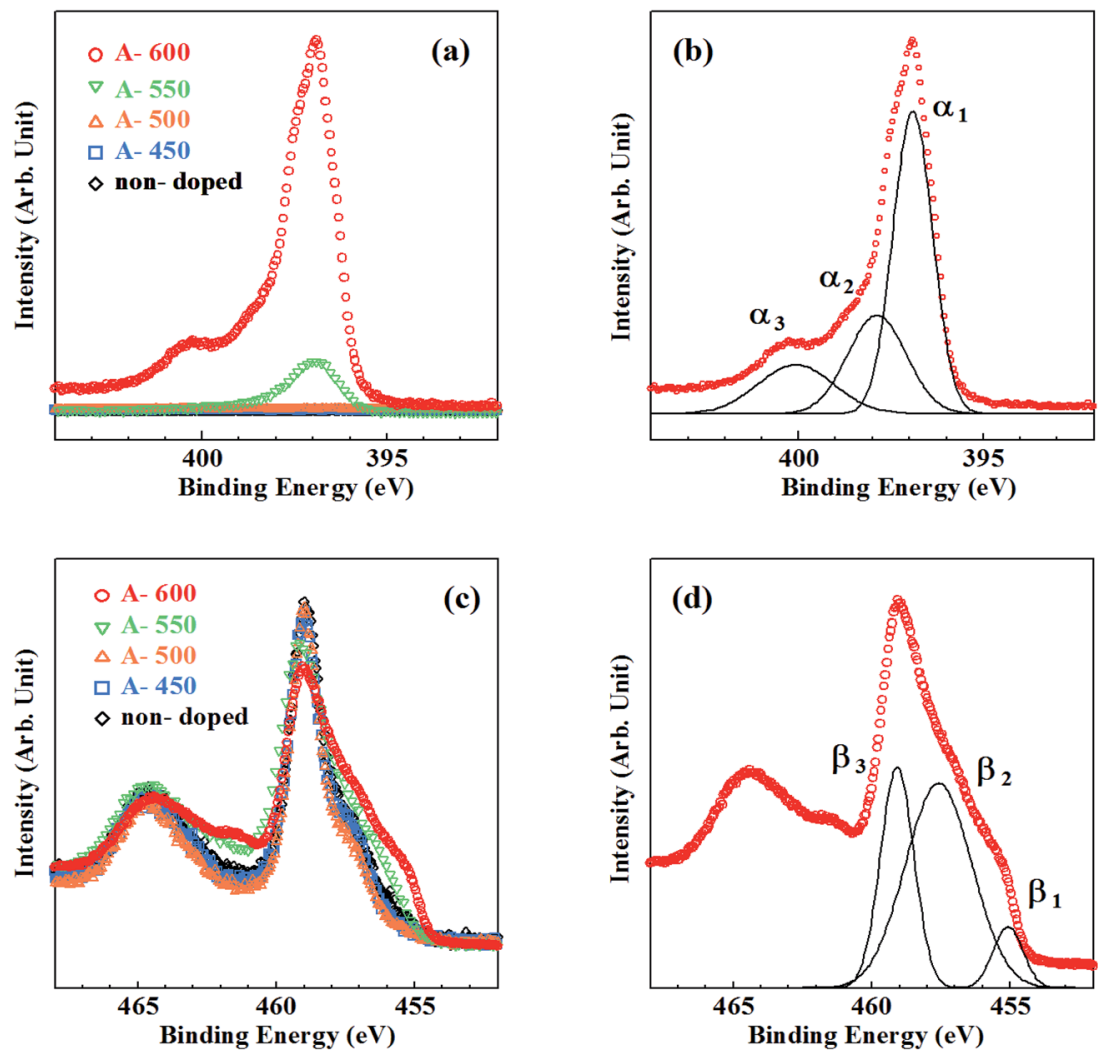

Fig. 2 Core-level XPS spectra for the samples synthesized by method A. (a) N1s spectra, (b) decomposition of N1s spectrum for A-600, (c) Ti2p spectra, (d) decomposition of Ti2p spectrum for A-600. 
two peaks at $E_{\text {bin }}=402$ and $400 \mathrm{eV}$ are due to molecularly chemisorbed $\mathrm{N}_{2}\left(\gamma-\mathrm{N}_{2}\right)$, while a peak observed at $E_{\text {bin }}=396 \mathrm{eV}$ is originated from substitutional $\mathrm{N}\left(\mathrm{N}_{\mathrm{s}}\right) \cdot{ }^{5} 403 \mathrm{eV}$ peak was ascribed to $\mathrm{Ti}-\mathrm{N}-\mathrm{O}$ bonds by Wang et al. ${ }^{22}$ Okato et al. rather assigned the peak at $E_{\text {bin }}=400 \mathrm{eV}$ to $\mathrm{Ti}-\mathrm{O}-\mathrm{N}$ linkage. ${ }^{3} \mathrm{O}-\mathrm{Ti}-\mathrm{N}$ linkage was responsible for the signal at $E_{\text {bin }}=399.2 \mathrm{eV},{ }^{23} 398.2 \mathrm{eV}^{24}$ and $401.3 \mathrm{eV}^{25} \mathrm{~N} 1 \mathrm{~s}$ peaks at around $E_{\mathrm{bin}}=400-401.5 \mathrm{eV}$ were supposed to be contribution of nitrogen compounds such as $\mathrm{NO}_{x}{ }^{26}$ Zhang et al. insisted that photoactive centers observed at $E_{\text {bin }}=399.8 \mathrm{eV}$ are complex $\left[\mathrm{O}^{2-}-\mathrm{Ti}^{4+}-\mathrm{N}^{3-}-\mathrm{Ti}^{4+}-\mathrm{V}_{\mathrm{O}}{ }^{-}\right]$clusters. ${ }^{12}$ On the other hand, Feng et al. revealed that the photoactive $400 \mathrm{eV}$ peaks are due to interstitial $\mathrm{NO}$ molecules bound to $\mathrm{V}_{\mathrm{O}}$ $\left(\mathrm{V}_{\mathrm{O}}-\mathrm{NO}\right) .{ }^{27}$ It was demonstrated that the peaks of $\mathrm{N}_{\mathrm{i}}$ appear at $E_{\text {bin }}>399 \mathrm{eV}^{28}$ and the peak at $E_{\text {bin }}=396-397 \mathrm{eV}$ is attributed to $\mathrm{N}_{\mathrm{s}}{ }^{29}$ respectively. Thus, according to the literature, $\mathrm{N}$ atoms are chiefly doped into $\mathrm{N}_{\mathrm{s}}$ sites at temperatures higher than $550{ }^{\circ} \mathrm{C}$ by method A. The peak position of $\alpha_{1}$ is near the binding energy of N1s in TiN $\left(E_{\mathrm{bin}}=397.2 \mathrm{eV}\right) .{ }^{29}$ Therefore, $\alpha_{1}$ is assigned to 'nitride peak', where $\mathrm{N}$ ions are in substitutional sites $\left(\mathrm{N}_{\mathrm{s}}\right)^{\mathbf{5 , 2 8 , 2 9}}$ $\alpha_{3}$ may be ascribed to $\mathrm{NO}_{x}$ (or Ti-O-N, Ti-N-O), where positively charged $\mathrm{N}$ is located at interstitial site $\left(\mathrm{N}_{\mathrm{i}}\right)$ or Ti-vacancy site $\left(\mathrm{N}_{\mathrm{Ti}}\right) .{ }^{14}$ On the other hand, $\alpha_{2}$ peak with the binding energy higher than $\alpha_{1}$ can be assigned to $\mathrm{N}$ ions with less negative charge than -2 . Thus, it is likely that $\mathrm{O}-\mathrm{Ti}-\mathrm{N}$ bonds are responsible for $\alpha_{2}$ because negative charge density on $\mathrm{N}$ is expected to be reduced from -2 due to higher electronegativity of $\mathrm{O}$ than $\mathrm{N}$. The possibility of $\mathrm{NH}_{\mathrm{x}}$ adsorbed on the surface should be ruled out because $\mathrm{N}$ species still remain after surface treatments $\left(\mathrm{Ar}^{+}\right.$sputtering and annealing). N/O atomic ratios deduced from N1s and O1s peaks were estimated to be 0.008 and 0.086 for A-550 and A-600, respectively. Table 1 lists the binding energies and ratios of $\alpha_{1}, \alpha_{2}, \alpha_{3}$ peaks and N/O atomic ratios.

The density of $\mathrm{N}_{\mathrm{s}}$ (in proportion to $\alpha_{1}$ and $\alpha_{2}$ peaks) is by far larger than that of $\mathrm{N}_{\mathrm{i}}$ (in proportion to $\alpha_{3}$ peak) at $550{ }^{\circ} \mathrm{C}$ and $600{ }^{\circ} \mathrm{C}$. This feature is in sharp contrast with the results of previous studies using $\mathrm{N}$ sources other than $\mathrm{NH}_{3}$ in sol-gel methods, where $\mathrm{N}_{\mathrm{i}}$ peaks are dominant. ${ }^{22,28,30}$ Incorporation of $\mathrm{N}$ into $\mathrm{N}_{\mathrm{i}}$ sites induces compressive stress in $\mathrm{TiO}_{2}$ lattices. Heavy
$\mathrm{N}_{\mathrm{i}}$ doping leads to the structural phase transformations into rutile phase. Hence, maximum density of $\mathrm{N}_{\mathrm{i}}$ remains small $(<1.5$ at\%). ${ }^{3}$ In contrast, $\mathrm{N}_{\mathrm{s}}$ doping with the density higher than 1.5 at $\%$ is possible due to smaller lattice distortion. ${ }^{29}$ However, because the binding energy of Ti-N is smaller than that of $\mathrm{Ti}-\mathrm{O}$, substitution of $\mathrm{O}$ by $\mathrm{N}$ hardly occurs spontaneously in $\mathrm{TiO}_{2}$. Reduction of $\mathrm{TiO}_{2}$ (i.e., production of $\mathrm{V}_{\mathrm{O}}$ ) is needed for incorporation of $\mathrm{N}$ into $\mathrm{N}_{\mathrm{s}}$ sites. $\mathrm{NH}_{3}$ is known to be decomposed at temperatures higher than $550{ }^{\circ} \mathrm{C} .{ }^{31}$ Atomic $\mathrm{H}$ produced by decomposition of $\mathrm{NH}_{3}$ removes $\mathrm{O}$ from $\mathrm{TiO}_{2}$ lattice (i.e., produce $\mathrm{V}_{\mathrm{O}}$ ) and promotes incorporation of $\mathrm{N}$ into $\mathrm{V}_{\mathrm{O}}$ sites. However, because decomposition occurs at temperatures higher than $550{ }^{\circ} \mathrm{C}$, the onset temperature of reduction of $\mathrm{TiO}_{2}$ and subsequent $\mathrm{N}$ incorporation using $\mathrm{NH}_{3}$ is $550{ }^{\circ} \mathrm{C}$.

Fig. 2(c) shows Ti2p XPS spectra for the samples synthesized by method $A$. Three contributions $\left(\beta_{1}, \beta_{2}\right.$ and $\left.\beta_{3}\right)$ were obtained by decomposition of Ti2 $\mathrm{p}_{3 / 2}$ peaks. One example for A-600 is shown in Fig. 2(d). A lot of researchers observed Ti2p XPS spectra in $\mathrm{TiO}_{2}$, TiN and TiON, and four kinds of peaks with different Ti chemical states were found..$^{12,17,27,32}$ Peaks associated with $\mathrm{Ti}^{4+}$ (in $\mathrm{TiO}_{2}$ ), $\mathrm{Ti}^{3+}$ (in reduced $\mathrm{TiO}_{2}$ or $\mathrm{N}-\mathrm{TiO}_{2}$ ) and $\mathrm{Ti}^{2+}$ (in TiN) were shown to appear at $E_{\text {bin }}=458.6-459.5 \mathrm{eV}, 456.7-$ $457.8 \mathrm{eV}$ and 454.8-456.0 eV, respectively. ${ }^{33-35}$ An 'additional peak' with positive charge between +3 and +4 originated from $\mathrm{Ti}$ in distorted lattices of $\mathrm{TiO}_{2}$ and $\mathrm{TiN}$ was shown to be observed at $E_{\text {bin }}=457.7-458.7 \mathrm{eV}$. Consequently, $\beta_{1}, \beta_{2}$ and $\beta_{3}$ can be assigned to $\mathrm{Ti}^{2+}, \mathrm{Ti}^{3+}$ and $\mathrm{Ti}^{4+}$ respectively.

In Fig. 3 , the ratios of $\beta_{1}, \beta_{2}$ and $\beta_{3}$ peaks as a function of calcination temperature are plotted by open circles. Small traces of $\beta_{2}$ peaks were recognized for the samples calcined below $500{ }^{\circ} \mathrm{C}(\sim 0.3)$. The ratios of $\beta_{3}(\sim 0.7)$ are almost equivalent to that for non-doped samples (indicated by a cross) and thus, the existence of $\beta_{2}$ peaks was not caused by $\mathrm{N}$ doping, but rather due to surface treatment of samples (i.e., $\mathrm{Ar}^{+}$sputtering and sequential annealing). However, $\beta_{3}$ peak steeply decreases and $\beta_{1}, \beta_{2}$ peaks grow at elevated calcination temperatures. This is in line with the rapid evolution of N1s peaks above $550{ }^{\circ} \mathrm{C}$.

As already mentioned, $\mathrm{TiO}_{2}$ must be reduced (i.e., $\mathrm{V}_{\mathrm{O}}$ is needed to be produced) prior to incorporation of $\mathrm{N}$ into $\mathrm{N}_{\mathrm{s}}$.

Table 1 The binding energies and ratios of $\alpha_{1}, \alpha_{2}, \alpha_{3}, \beta_{1}, \beta_{2}$ and $\beta_{3}$ peaks and N/O atomic ratios for N-TiO 2 and non-doped samples. "N.D." means "no detection"

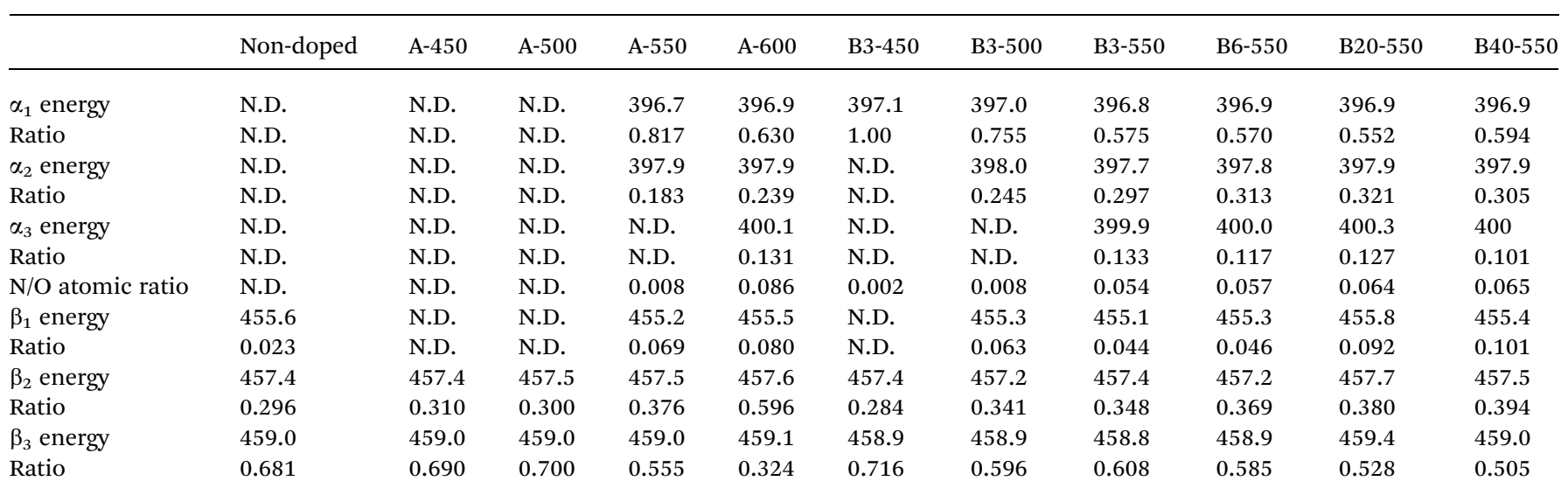




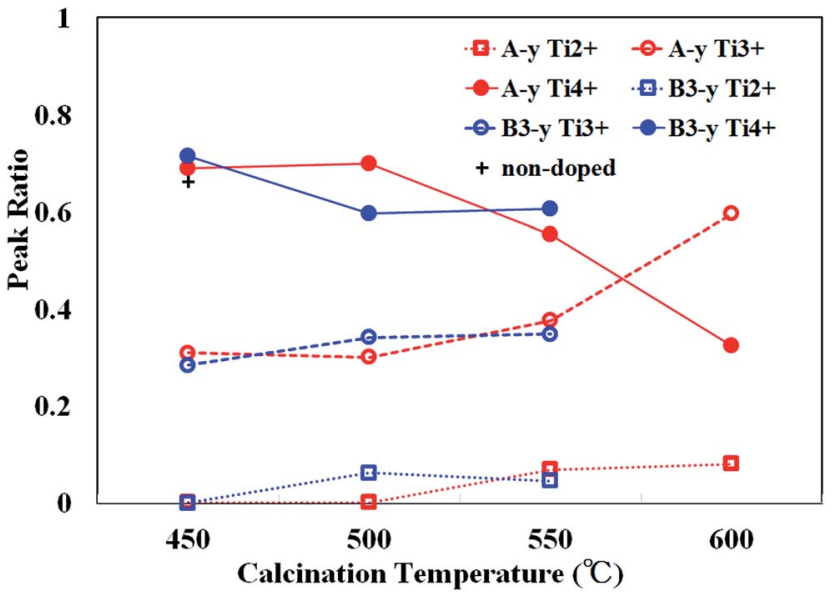

Fig. 3 The peak ratios of $\mathrm{Ti}^{2+}\left(\beta_{1}\right), \mathrm{Ti}^{3+}\left(\beta_{2}\right)$ and $\mathrm{Ti}^{4+}\left(\beta_{3}\right)$ for the samples synthesized by method $A(A-y$, red) and $B(B 3-y$ : blue) as a function of calcination temperature $(y)$. The ratio of $\mathrm{Ti}^{4+}\left(\beta_{3}\right)$ for non-doped sample is indicated by a cross.

Reduction of $\mathrm{TiO}_{2}$ is evidenced by the appearances of reduced $\mathrm{Ti}$ species $\left(\mathrm{Ti}^{3+}\right.$ and $\left.\mathrm{Ti}^{2+}\right)$. Therefore, the reduction of $\mathrm{TiO}_{2}$ takes place at $550{ }^{\circ} \mathrm{C}$. This onset temperature is consistent with the decomposition temperature of $\mathrm{NH}_{3}$ and therefore, the reduction and subsequent $\mathrm{N}$ incorporation are indeed caused by atomic $\mathrm{H}$ generated by decomposition of $\mathrm{NH}_{3} \cdot{ }^{36}$ The present results are supported by theoretical prediction showing that the introduction of $\mathrm{V}_{\mathrm{O}}$ stabilizes the formation of $\mathrm{N}_{\mathrm{s}} \cdot{ }^{37-39}$

Fig. 4 shows the XPS spectra of the samples prepared by method B, where the amount of urea dopant was fixed at 3 at $\%$. N1s XPS spectra are shown in Fig. 4(a). Peaks at $E_{\text {bin }} \sim 397 \mathrm{eV}$ were seen in Fig. 4(a) for all samples, while a very small peak was observed at $E_{\text {bin }} \sim 400 \mathrm{eV}$ only for the sample calcined at $550{ }^{\circ} \mathrm{C}$. Decomposition of observed N1s spectra in a manner similar to Fig. 2(b) gives rise to $\alpha_{1}, \alpha_{2}$ and $\alpha_{3}$ peaks, again (Fig. 4(b)). In Table 1, detailed data on N1s states are listed. Only a small amount of $\mathrm{N}$ was incorporated in B3-450. Substantial $\mathrm{N}$ doping took place at $500{ }^{\circ} \mathrm{C}$. The $\mathrm{N}$ peak grew further at $550{ }^{\circ} \mathrm{C}$. Therefore, the onset temperature of $\mathrm{N}$ doping is at least $50{ }^{\circ} \mathrm{C}$ lower by using urea. N/O ratio for B3-550 is by far larger than that for A-550, whereas smaller than that for A-600. N/O ratios are evaluated to be $0.002,0.008$ and 0.054 for B3-450, B3-500 and B3-550, respectively.

Ti2p XPS spectra are shown in Fig. 4(c). They were also composed of three fundamental peaks $\left(\beta_{1}, \beta_{2}\right.$ and $\left.\beta_{3}\right)$ associated with $\mathrm{Ti}^{2+}, \mathrm{Ti}^{3+}$ and $\mathrm{Ti}^{4+}$ (Fig. 4(d)). The changes in the ratio of $\beta_{1}$, $\beta_{2}$ and $\beta_{3}$ with the rise in calcination temperature are revealed by blue symbols and lines in Fig. 3 .

$\mathrm{N}$ density is closely related to the development of $\beta_{1}, \beta_{2}$ peaks and the declination of $\beta_{3}$ peak. As shown in Fig. $3, \beta_{3}$ peak ratio of B3-450 is almost equivalent to those of A-450, A-500 and non-doped sample, indicating that reduction of $\mathrm{TiO}_{2}$ hardly
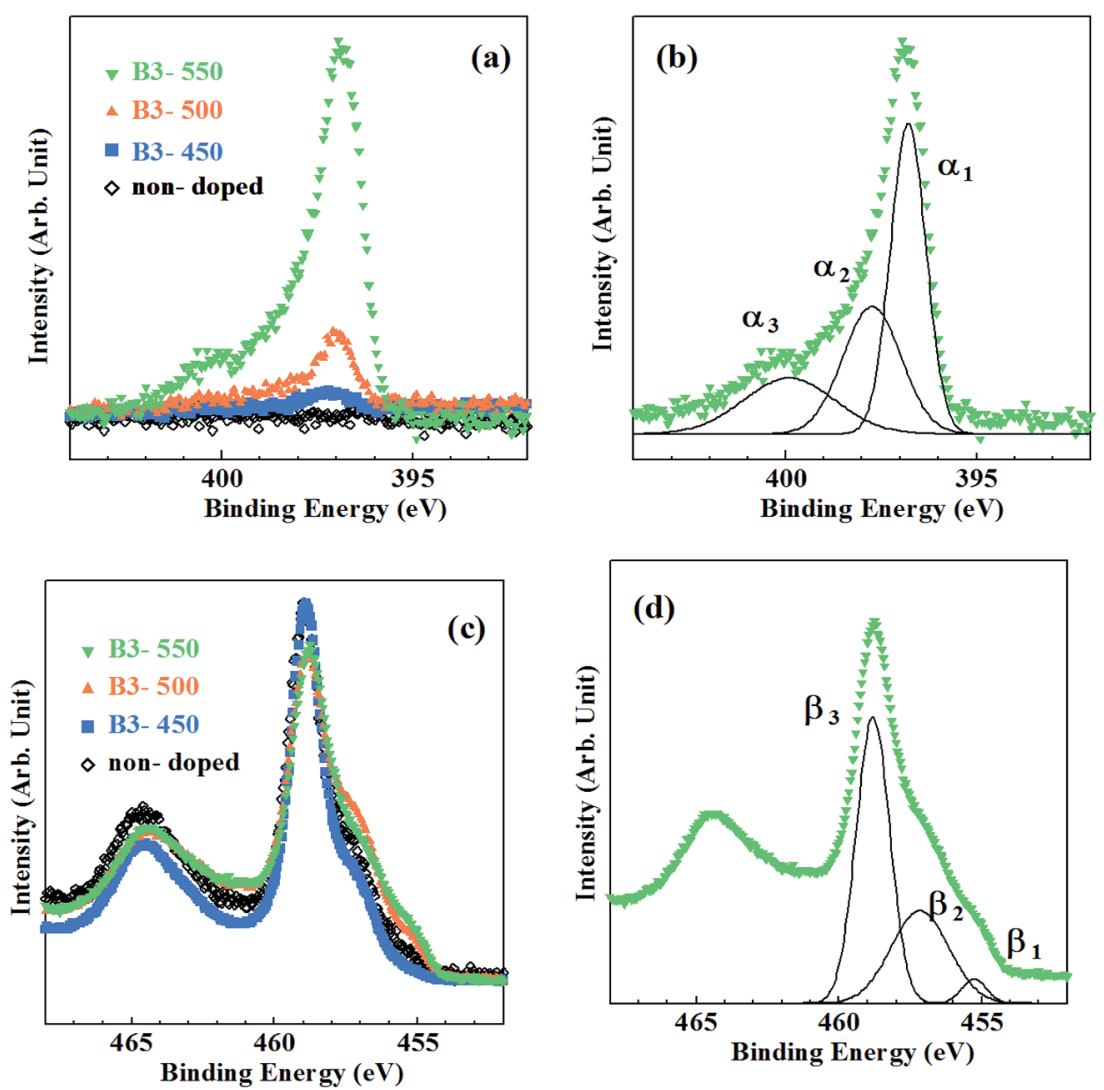

Fig. 4 Core-level XPS spectra for the samples synthesized by method B. (a) N1s spectra, (b) decomposition of N1s spectrum for B3-550, (c) Ti2p spectra, (d) decomposition of Ti2p spectrum for B3-550. 
occurred in B3-450. However, $\beta_{3}$ peak ratio distinctly decreased and $\beta_{1}, \beta_{2}$ peak ratios increased at $500{ }^{\circ} \mathrm{C}$. These phenomena correspond to the onset of substantial $\mathrm{N}$ doping at $500{ }^{\circ} \mathrm{C}$ for the samples synthesized by method $\mathrm{B}$. It can be ascribed to urea. Urea was shown to be decomposed into $\mathrm{NH}_{3}$ and biuret. ${ }^{40}$ The reductant source of urea is isolated $\mathrm{NH}_{3}$. However, the role of urea in the present study is apparently different from that of $\mathrm{NH}_{3}$ in that the former act as a $\mathrm{N}$ reagent even at $500{ }^{\circ} \mathrm{C}$. Urea may be dissociated not into $\mathrm{NH}_{3}$ but directly into $\mathrm{N}$ and $\mathrm{H}$ at $500{ }^{\circ} \mathrm{C}$ although the evidence is absent.

We have also changed the amount of urea to investigate the influence on the electronic properties. All films were synthesized at $550{ }^{\circ} \mathrm{C}$. As can be seen in Fig. S1(a), $\uparrow$ the intensity of N1s peak slightly increased with increasing the amount of urea. N/O atomic ratios were estimated to be $0.054,0.057,0.064$ and 0.065 for B3-550, B6-550, B20-550 and B40-550, respectively. Fig. S1(b) $\dagger$ shows Ti2p XPS spectra for these samples. Ratios of $\beta_{1}, \beta_{2}$ and $\beta_{3}$ peaks are given in Table 1 . Although the reduction of $\mathrm{TiO}_{2}$ was slightly enhanced with the increase in urea dosage, the extent of reduction did not strongly depend on the amount of urea. Therefore, the reduction activity of urea at $550{ }^{\circ} \mathrm{C}$ is almost saturated at $3 \%$.

\subsection{Extended structures of $\mathrm{VB}$ edge}

The VB XPS spectra measured using synchrotron radiation are shown in Fig. 5(a) and (b) for samples synthesized by method A and $\mathrm{B}$ together with non-doped samples, respectively. There have been carried out several studies on VB spectra of $\mathrm{N}-\mathrm{TiO}_{2}$ measured using XPS. ${ }^{10,32,41-43}$ However, most of them used X-ray tubes as a X-ray source and spectra with low quality made it difficult to discuss minutely the features of band gap states and the changes in VB structures induced by N doping. Synchrotron radiation is suitable as a X-ray source for measurement of VB spectra with high $\mathrm{S} / \mathrm{N}$ ratios owing to its high intensity.

The VB edges for A-450, A-500 and B3-450 coincide with that for non-doped sample, while those for A-550, A-600, B3-500 and $\mathrm{B} x-550$ (where $x=3,6,20,40$ ) are extended into band gap with smaller binding energies. In particular, remarkable shoulder structures were recognized for A-600 and B3-550. Separate peaks at $E_{\text {bin }} \approx 0.8 \mathrm{eV}$ are associated with $\mathrm{Ti}^{3+}$ species. ${ }^{39,43}$

The VB structures of non-doped anatase $\mathrm{TiO}_{2}$ have been investigated by angle-resolved photoelectron spectroscopy (ARPES) in detail. ${ }^{21}$ The VB of anatase is mainly composed of O2p states with a minor contribution of Ti3d states, lying between 4 and $10 \mathrm{eV}$ below Fermi level. The VB XPS spectra are characterized by two intense peaks at smaller and larger binding energy regions and weak emission structures in between them. These features have already been identified by photoemission studies. ${ }^{44}$ One of the intense peaks at $E_{\text {bin }}=4-$ $5 \mathrm{eV}$ is associated with $\mathrm{O} 2 \mathrm{p}$-derived $\mathrm{P}_{\pi}$ nonbonding band, while the other at $E_{\text {bin }}=7-9 \mathrm{eV}$ is ascribed to $\sigma$ bonding band formed by $\mathrm{Ti} \mathrm{e}_{\mathrm{g}}$ and $\mathrm{O} 2 \mathrm{p}_{\sigma}$ states. Weak emissions correspond to $\pi$-bonding band formed by $\mathrm{Ti} \mathrm{t}_{2 \mathrm{~g}}$ and $\mathrm{O} 2 \mathrm{p}_{\pi}$ states. Another ARPES measurement using linearly-polarized synchrotron radiation demonstrated that $\pi$-bonding band is resolved into two peaks with different polarization dependence, i.e., the shallower peak $\left(\pi_{1}\right)$ at $E_{\text {bin }} \approx 5 \mathrm{eV}$ and the deeper peak $\left(\pi_{2}\right)$ at $E_{\text {bin }} \approx 6 \mathrm{eV}^{45} \mathrm{An}$ "angle-integrated" XPS spectrum of VB for non-doped sample in this study was also successfully decomposed into four bands $\left(\mathrm{P}_{\pi}, \pi_{1}, \pi_{2}, \sigma\right)$, similar to previous ARPES study. ${ }^{21,45}$ The balance band maximum (VBM) of non-doped sample was estimated to be $3.7 \mathrm{eV}$ below Fermi level by linearly extrapolating slope of VB edge. The position of conduction band minimum (CBM) and band gap are also crucial for photocatalytic activity. ${ }^{\mathbf{4 6 4}}$ The band gap was successfully determined to be $3.2 \mathrm{eV}$ in the recent study of time-resolved photoelectron spectroscopy (TRPES). ${ }^{\mathbf{4 8 4}}$ According to the results of TRPES, $\mathrm{TiO}_{2}$ bands were shown to bend downwardly from the bulk to the surface. The magnitude of downward band bending ranged from 0 to $0.8 \mathrm{eV}$, depending on the surface conditions such as surface-specific structures and the density and/or the type of surface defects. It was estimated to be $0.5 \mathrm{eV}$ in the present study. Therefore, the position of VBM is likely to be reliable. Then, CBM was indirectly estimated to be $0.5 \mathrm{eV}$ below Fermi level.

Decomposition of all VB XPS spectra for samples synthesized by method $\mathrm{A}$ and $\mathrm{B}$ reproduced four bands $\left(\mathrm{P}_{\pi}, \pi_{1}, \pi_{2}, \sigma\right)$.
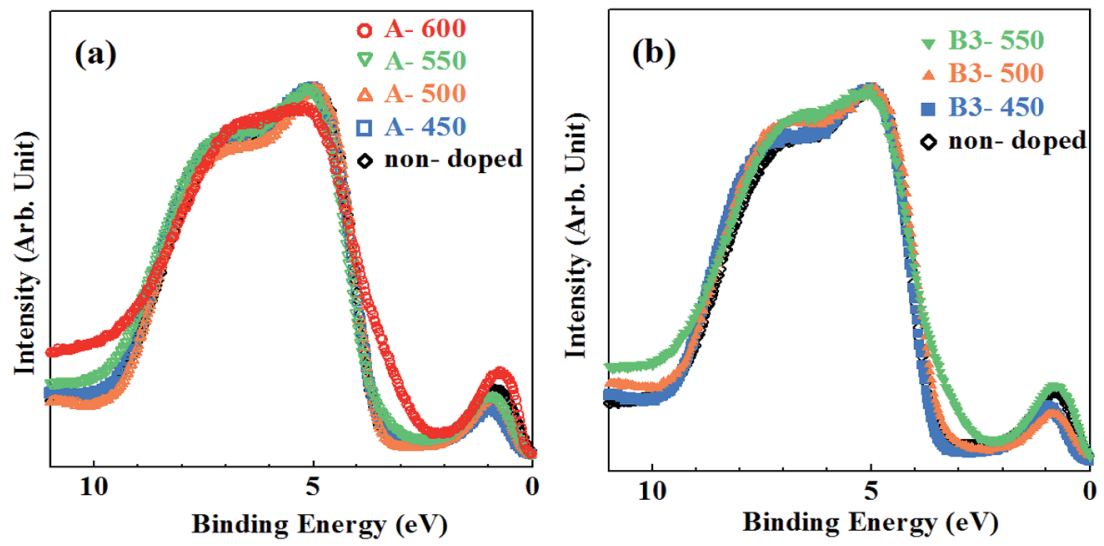

Fig. 5 The VB XPS spectra for samples synthesized by (a) method A with non-doped sample and (b) method B (urea: 3\%) with non-doped sample. 
However, the fifth new peaks apparently appeared for A-600 and $\mathrm{B} x-550$ (where $x=3,6,20,40$ ) on the smaller binding energy side of $\mathrm{P}_{\pi}$ band. They are originated from shoulder structures of VB edges and are clearly induced by $\mathrm{N}$ doping. They disappeared (under detection limit) for A-450, A-500, A-550, B3-450 and B3500. The results of decomposition of VB spectra for A-600 and B3-550 are shown in Fig. 6(a) and (b), respectively. The peak energies, widths (FWHM) and the ratios of areas of all VB bands,
$\mathrm{N}$-derived states and $\mathrm{Ti}^{3+}$ defect states for non-doped sample and $\mathrm{N}-\mathrm{TiO}_{2}$ samples are summarized in Table 2, where the ratio of area is defined to be the division of area of each peak by total VB area.

In particular, peak energies of $\mathrm{N}$-derived states range between $0.24 \mathrm{eV}$ and $0.34 \mathrm{eV}$ above VBM in the band gap, which are larger than $\sim 0 \mathrm{eV}$ by $\mathrm{UPS}^{43}$ and $0.04-0.13 \mathrm{eV}$ by UV-vis optical absorption experiments, ${ }^{24,50}$ while smaller than $0.52 \mathrm{eV}$
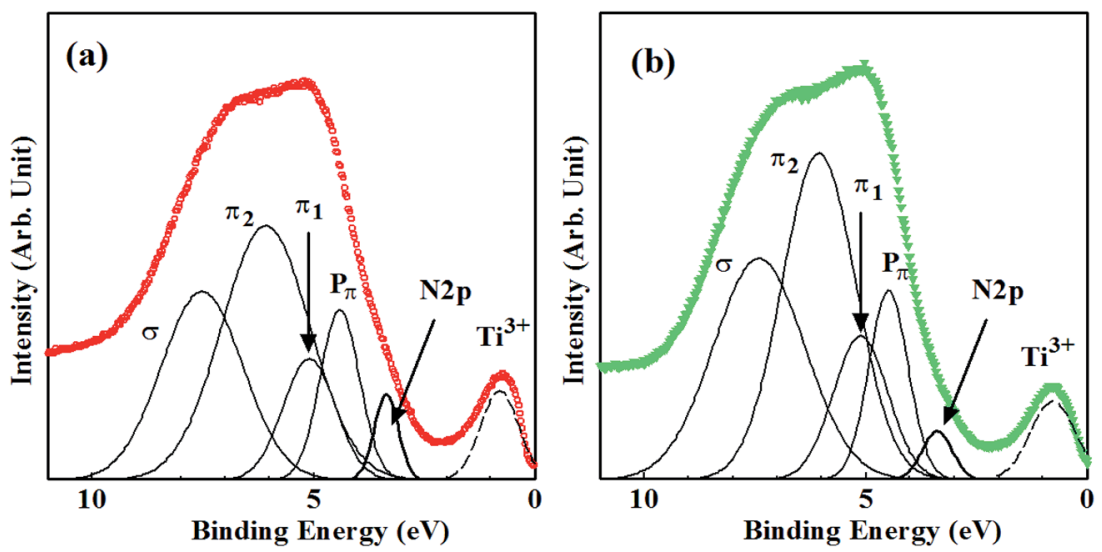

Fig. 6 Decomposition of the VB XPS spectra for (a) A-600 and (b) B3-550.

Table 2 The peak energies $\left(E_{\text {bin }}\right)$, widths (FWHM) and the ratios of areas of VB bands, $\mathrm{N}$-derived states and Ti ${ }^{3+}$ defect states for non-doped and $\mathrm{N}-\mathrm{TiO}_{2}$ samples

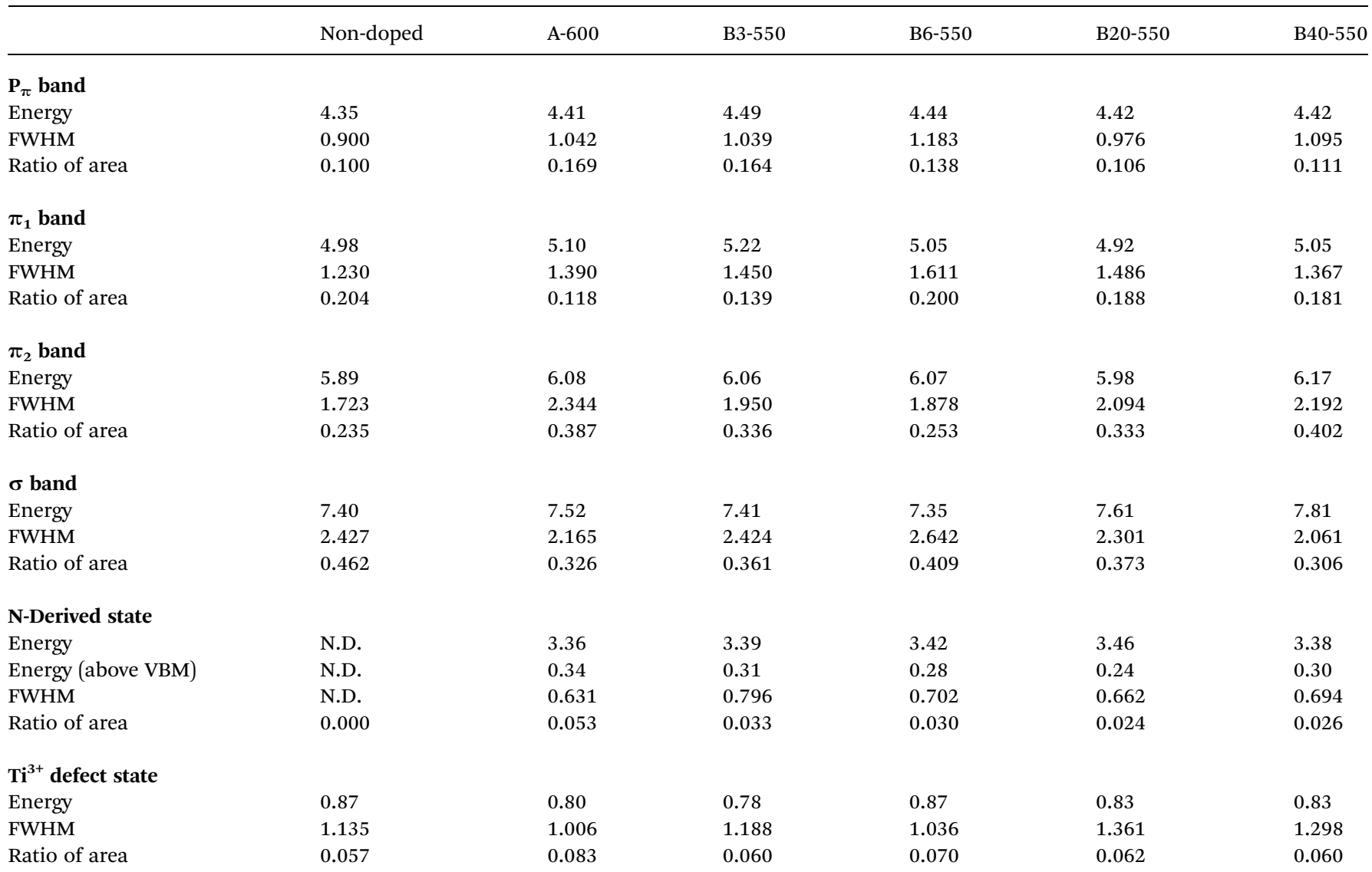




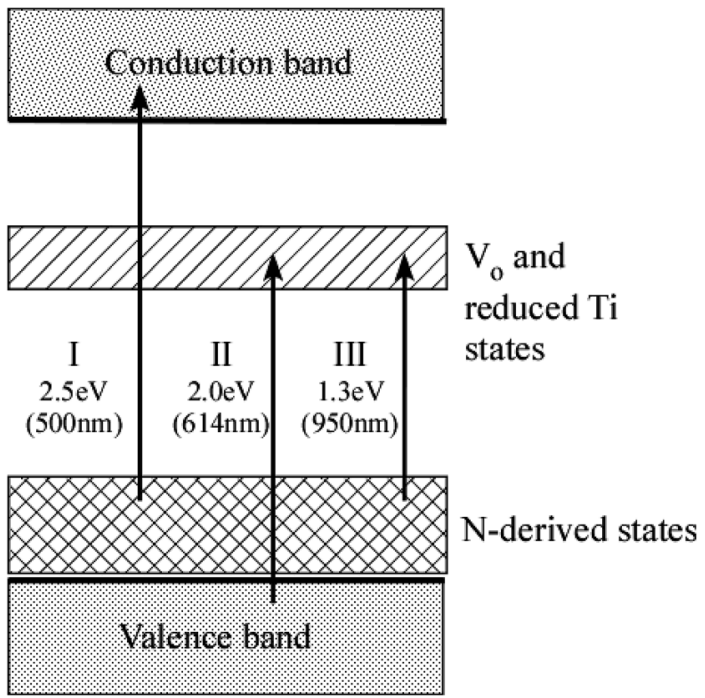

Fig. 7 The energy diagram of $\mathrm{N}-\mathrm{TiO}_{2}$. Arrows denote three kinds of transition of electrons induced by absorption of vis light. The energy level of $V_{O}$ and reduced Ti states was quoted from the literature. ${ }^{15}$ Numerical values given below each transition represent the smallest energy and longest wavelength capable of inducing transition, respectively.

by deep-level optical spectroscopy ${ }^{6}$ and $0.75 \mathrm{eV}$ by photocurrent measurement. ${ }^{51}$

It was insisted that $\mathrm{N}$-derived states in $\mathrm{N}-\mathrm{TiO}_{2}$ form 'hybridized' VB with O2p states. ${ }^{5}$ However, other studies have shown that $\mathrm{N}$ atoms incorporated in $\mathrm{TiO}_{2}$ generate $\mathrm{N}$-derived 'localized' states in the band gap. ${ }^{43,52-54}$ As shown in Table 2, the findings that both FWHM and areas of new peaks induced by $\mathrm{N}$ doping are very small compared with VB and that four bands (in particular, $\mathrm{P}_{\pi}$ band) are hardly affected by $\mathrm{N}$ doping imply that they are 'localized' from VB rather than 'hybridized' with VB of $\mathrm{TiO}_{2}{ }^{43}$ although the larger binding energy sides of them are slightly overlapped with $\mathrm{VB}$ of $\mathrm{TiO}_{2}$. $\mathrm{N}$ doping into $\mathrm{N}_{\mathrm{s}}$ inevitably accompanies the production of $\mathrm{V}_{\mathrm{O}}$ and reduced $\mathrm{Ti}$ species $\left(\mathrm{Ti}^{3+}, \mathrm{Ti}^{2+}\right)$. They form 'defect states' in upper half of the band gap. ${ }^{15}$ Therefore, such defect states are also likely to have small effect on VB structures of $\mathrm{TiO}_{2}$.

The energy diagram of $\mathrm{N}-\mathrm{TiO}_{2}$ is illustrated in Fig. 7. The wavelength of vis light absorbed by $\mathrm{N}-\mathrm{TiO}_{2}$ must be shorter than approximately $500 \mathrm{~nm}$ (i.e., the energy of light $\geq 2.5 \mathrm{eV}$, transition I in Fig. 7) according to the peak energies and FWHM of N-derived states listed in Table 2. It is in excellent agreement with typical UV-vis optical absorption spectra for $\mathrm{N}-\mathrm{TiO}_{2}$ showing the onset wavelength of absorption at $\sim 500 \mathrm{~nm}$. $^{5,11,38,55}$ However, the absorption spectra for $\mathrm{N}-\mathrm{TiO}_{2}$ with heavy $\mathrm{N}$ doping or those subjected to high-temperature annealing were extended into the wavelength longer than $500 \mathrm{~nm}$, which was attributable to the absorption associated with $\mathrm{V}_{\mathrm{O}}$ and reduced Ti defect states. ${ }^{52,56,57}$ In reality, it was demonstrated that $\mathrm{V}_{\mathrm{O}}$ states produced in plasma-treated $\mathrm{TiO}_{2}$ are responsible for the absorption at wavelength between $506 \mathrm{~nm}$ and $614 \mathrm{~nm}$ (related to the transition II from VB to $\mathrm{V}_{\mathrm{O}}$ and reduced Ti defect states). ${ }^{15}$
Then, the transition from $\mathrm{N}$-derived states to $\mathrm{V}_{\mathrm{O}}$ and reduced $\mathrm{Ti}$ defect states (transition III) accounts for the absorption at wavelength from $614 \mathrm{~nm}$ to $950 \mathrm{~nm}$.

According to DFT calculations, $\mathrm{N}_{\mathrm{s}}$ produces half-occupied $\mathrm{N}$-derived states slightly $(0.14 \mathrm{eV})$ above VBM, while $\mathrm{N}_{\mathrm{i}}$ also generates anti-bonding localized states due to $\mathrm{N}-\mathrm{O} \pi$ bonds (but higher, $0.73 \mathrm{eV}$ ) above VBM. ${ }^{28}$ Therefore, it is likely that peak energies of $\mathrm{N}$-derived states of $\mathrm{N}_{\mathrm{s}}$ listed in Table 2 are a little larger than theoretically predicted value $(0.14 \mathrm{eV}$ above VBM). Another DFT calculation demonstrated that the formation energy of oxygen vacancy $\left(\mathrm{V}_{\mathrm{O}}\right)$ is drastically reduced by substitution of $\mathrm{O}$ by $\mathrm{N}^{42}$ This explains why $\mathrm{N}_{\mathrm{s}}$ is promoted in the presence of $\mathrm{V}_{\mathrm{O}}$. When one $\mathrm{N}$ atom simply replaces one $\mathrm{O}^{2-}$ ion in $\mathrm{TiO}_{2}$ lattices, one $\mathrm{N}$-derived state is singly occupied because the number of $2 p$ electrons is smaller in $\mathrm{N}$ (3) than that in $\mathrm{O}(4)$. If $\mathrm{V}_{\mathrm{O}}$ coexists with $\mathrm{N}_{\mathrm{s}}$, there are two possibilities in spin configuration. One is the high-spin configuration where one electron is trapped by $\mathrm{V}_{\mathrm{O}}$ site (i.e., $\mathrm{Ti}^{3+}$ site), whereas the other is trapped by a $\mathrm{N}$-derived state and spins of them are parallel. The other possibility is the low-spin configuration where two electrons originated from one $\mathrm{V}_{\mathrm{O}}$ are trapped by a $\mathrm{N}$-derived state and thus, a $\mathrm{N}$-derived state is fully occupied and spins of electrons are anti-parallel. The latter configuration is always more stable than the former one because $V_{O}$ states are higher in energy than N-derived states (see Fig. 7). Thus, the low-spin configuration is more favorable than the high-spin configuration, which was supported by the results of EPR measurement. ${ }^{28}$ In the low-spin configuration, the energy levels of $\mathrm{N}$-derived states are almost equivalent, i.e., $0.59 \mathrm{eV}$ and $0.75 \mathrm{eV}$ above VBM for $\mathrm{N}_{\mathrm{s}}$ and $\mathrm{N}_{\mathrm{i}}$, respectively. The increase in energy from high-spin to low-spin configuration is larger for $\mathrm{N}_{\mathrm{s}}$ due to the difference in orbital nature. Photovoltage and impedance measurements have shown that $\mathrm{V}_{O}$ sites are much more numerous than doped $\mathrm{N}$ atoms, which suggests that lowspin configuration is realized. ${ }^{58}$ Another EPR measurement demonstrated that only electrons in low-spin configuration contribute to vis light activities. ${ }^{31}$ However, the energy levels of $\mathrm{N}$-derived states listed in Table 2 are smaller than those for $\mathrm{N}_{\mathrm{s}}$ in the low-spin configuration (0.59 eV above VBM), whereas larger than those for $\mathrm{N}_{\mathrm{s}}$ in the high-spin configuration $(0.14 \mathrm{eV}$ above VBM). Therefore, it cannot be determined which spin configuration is achieved from the present results. Recent DFT calculation has shown that the formation energy of $\mathrm{N}_{\mathrm{Ti}}$ (substitution of Ti by $\mathrm{N}$ ) is always lower than those of $\mathrm{N}_{\mathrm{s}}$ and $\mathrm{N}_{\mathrm{i}}{ }^{14}$ In this case, $\mathrm{N}$ is located at Ti-vacancy site to form $\mathrm{NO}^{3-}$ (nitrate) or $\mathrm{NO}^{2-}$ (nitrite) with neighboring $\mathrm{O}^{2-}$. These $\mathrm{O}^{2-}$ ions experience local electronic potential different from those of ordinary $\mathrm{O}^{2-}$ ions, which leads to the formation of localized states above VB in the band gap. The energy level of them was estimated to be only $0.1 \mathrm{eV}$ above VBM. These states had large DOS (density of state) with $\mathrm{P}_{\pi}$ character and accompanied urbach tail into the band gap region, resulting in the absorption of vis light. However, this is not the case with the present study because the ratio of $\alpha_{3}$ peak due to $\mathrm{NO}_{x}$ was very small, as shown in Table 1. Hence, the origin of $\mathrm{N}$-derived states in Table 2 is $\mathrm{N}_{\mathrm{s}}$ rather than $\mathrm{N}_{\mathrm{i}}$ or $\mathrm{N}_{\mathrm{Ti}}$. 

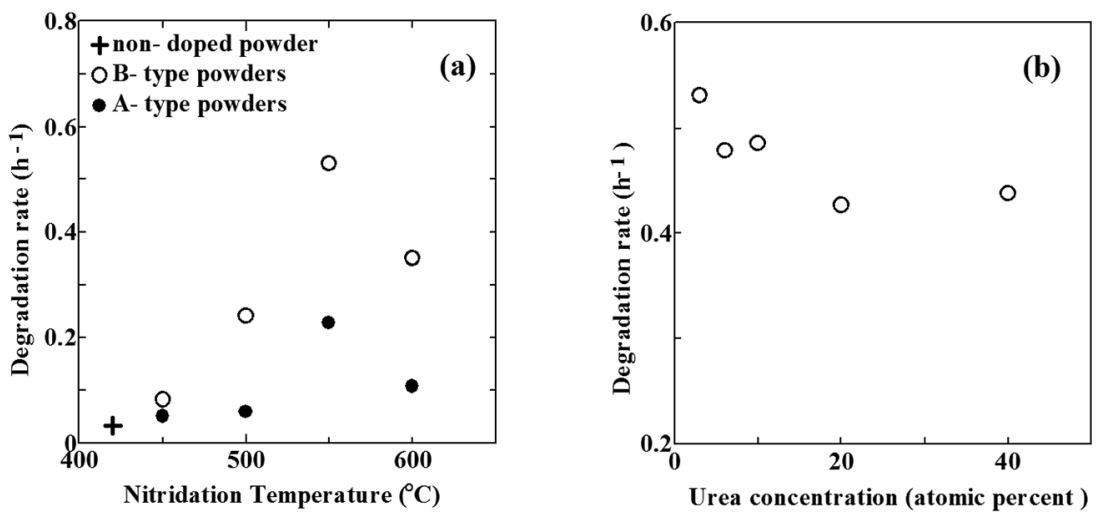

Fig. 8 (a) The degradation rates of MB as a function of nitridation temperature for A-type powders (closed circles), B-type powders (open circles) and non-doped $\mathrm{TiO}_{2}$ powder (cross). (b) The change in the degradation rate of MB with the concentration of urea for $\mathrm{B}$-type powders nitrided at $550{ }^{\circ} \mathrm{C}$.

\subsection{Photocatalytic activities}

Photocatalytic activities of $\mathrm{N}-\mathrm{TiO}_{2}$ powders were evaluated by degradation of $\mathrm{MB}$ under vis light irradiation. The concentration of $\mathrm{MB}$ in aqueous solution exponentially decreased with exposure time. Degradation rate is represented by time constant of degradation per hour $\left(\mathrm{h}^{-1}\right)$.

Fig. 8(a) reveals the degradation rates of $\mathrm{MB}$ using $\mathrm{N}-\mathrm{TiO}_{2}$ powders without urea (referred to as A-type powders, filled circles) and $\mathrm{N}-\mathrm{TiO}_{2}$ powders with urea (referred to as B-type powders, open circles) as a function of temperature in $\mathrm{NH}_{3}$ gas, respectively. The degradation rate increased with elevating temperature and reached a maximum at $550{ }^{\circ} \mathrm{C}$, followed by a rapid decrease with the further elevation of nitridation temperature for both types. This trend with nitridation temperature coincides with the previous studies for $\mathrm{N}-\mathrm{TiO}_{2}$ powders obtained by sol-gel method and post nitridation in $\mathrm{NH}_{3}$ gas. ${ }^{12,27,56}$ The optimum nitridation temperature giving highest degradation rate was $550{ }^{\circ} \mathrm{C}$, regardless of whether urea was used or not. However, the degradation rate was always larger for B-type powders than A-type powders, compared at the same temperature. Hence, urea was shown to improve photocatalytic activity under vis light. Moreover, there are considerable differences between the degradation of two types.

In case of A-type powders, the degradation rates of MB under vis light irradiation were very low below $500{ }^{\circ} \mathrm{C}$. They were almost similar to that of non-doped powder indicated by a cross in Fig. 8(a). It reflects small densities of $\mathrm{N}$ (under detection limit), as shown in Table 1. At the elevated temperature of $550{ }^{\circ} \mathrm{C}$, the degradation rate abruptly increased. This increase corresponds to substantial $\mathrm{N}$ doping due to the onset of decomposition of $\mathrm{NH}_{3}$, as already mentioned. However, the degradation rate decreased with further elevation of temperature to $600{ }^{\circ} \mathrm{C}$. The generation of defects is needed for incorporation of $\mathrm{N}$ into $\mathrm{N}_{\mathrm{s}}$. Taking the $\mathrm{N} / \mathrm{O}$ atomic ratios and $\beta_{1}, \beta_{2}$ ratios into account, defect densities are likely to be always larger than $\mathrm{N}$ densities. It indicates that a number of defects $\left(\mathrm{V}_{\mathrm{O}}\right)$ remain unfilled with $\mathrm{N}$. Since reduction power of $\mathrm{NH}_{3}$ was relatively low, the number of such unfilled defects was still small at $550{ }^{\circ} \mathrm{C}$. However, the reduction power greatly increased at $600{ }^{\circ} \mathrm{C}$. Consequently, the density of defects unfilled with $\mathrm{N}$ became extremely large, giving rise to the steep decrease of degradation rate at $600{ }^{\circ} \mathrm{C}$ in spite of the increase in $\mathrm{N} / \mathrm{O}$ atomic ratio from 0.008 at $550{ }^{\circ} \mathrm{C}$ to 0.086 at $600{ }^{\circ} \mathrm{C}$. Highest vis light activity is obtained at $\mathrm{N} / \mathrm{O}$ ratio of $\sim 0.01$ at $550{ }^{\circ} \mathrm{C}$ for A-type powders. This is mostly in line with optimum $\mathrm{N}$ density of 1$2 \%,{ }^{3} \mathrm{~N} / \mathrm{Ti}$ ratio of $1.73 \%$ (ref. 59 ) and N/O ratio of $0.017,{ }^{5} 0.003 .{ }^{52}$ On the other hand, aqueous $\mathrm{NH}_{3}$ solution has also been utilized for production of $\mathrm{N}-\mathrm{TiO}_{2} \cdot{ }^{22,24,59}$ A notable feature of $\mathrm{NH}_{3}$ solution is that $\mathrm{N}-\mathrm{TiO}_{2}$ can be synthesized at temperatures as low as $260{ }^{\circ} \mathrm{C}$, which enables the formation of $\mathrm{N}-\mathrm{TiO}_{2}$ films on thermally-weak organic materials. However, unlike $\mathrm{NH}_{3}$ gas, $\mathrm{NH}_{3}$ solution has no reduction power since atomic $\mathrm{H}$ is never generated from the solution. This was supported by the finding that only $\mathrm{N}_{\mathrm{i}}$ was formed in $\mathrm{N}-\mathrm{TiO}_{2}$ fabricated from $\mathrm{NH}_{3}$ solution.

In case of B-type powders, the degradation rate was also very low at $450{ }^{\circ} \mathrm{C}$ due to small $\mathrm{N}$ density. It steeply increased at $500{ }^{\circ} \mathrm{C}$. This increase obviously arises from the increase in N/O atomic ratio. Therefore, urea substantially begins to act as a reductant and a $\mathrm{N}$ source at $500{ }^{\circ} \mathrm{C}$. Further increase in the degradation rate at $550{ }^{\circ} \mathrm{C}$ is also caused by the increase in $\mathrm{N}$ density. Since the effect of $\mathrm{NH}_{3}$ is still low at $550{ }^{\circ} \mathrm{C}$, this increase from $500{ }^{\circ} \mathrm{C}$ to $550{ }^{\circ} \mathrm{C}$ is greatly indebted to the enhanced ability of urea as a reductant and a $\mathrm{N}$ source. Therefore, the onset temperature of $\mathrm{N}$ doping for B-type powders is at least 50 degrees lower than that for A-type powders. In this respect, the nitriding ability of urea at $550{ }^{\circ} \mathrm{C}$ compares to that of $\mathrm{NH}_{3}$ at $600{ }^{\circ} \mathrm{C}$. However, the reduction power of urea at $550{ }^{\circ} \mathrm{C}$ is not so large as that of $\mathrm{NH}_{3}$ at $600{ }^{\circ} \mathrm{C}$ because the densities of $\beta_{1}$ and $\beta_{2}$ in B3-550 are considerably smaller than those in A600. Then, the density of defects unfilled with $\mathrm{N}$ in B-type powders nitrided at $550{ }^{\circ} \mathrm{C}$ is much smaller than that in $\mathrm{A}$ type powders nitrided at $600{ }^{\circ} \mathrm{C}$. This leads to by far higher degradation rate of B-type powders nitrided at $550{ }^{\circ} \mathrm{C}$ than that of A-type powders nitrided at $600{ }^{\circ} \mathrm{C}$. However, the degradation rate of B-type powders steeply decreased at $600{ }^{\circ} \mathrm{C}$. The reason for it is possibly the same as the case of A-type powders at $600{ }^{\circ} \mathrm{C}$, namely, high-density defects were produced due to the enhanced reduction power of $\mathrm{NH}_{3}$ at $600{ }^{\circ} \mathrm{C}$. Consequently, the 
optimum N/O ratio giving highest degradation rate is $\sim 0.06$ (corresponding to $\mathrm{N}$ density of 4 at\%) at $550{ }^{\circ} \mathrm{C}$ for B-type powders. This optimum $\mathrm{N}$ density ( 4 at\%) of the present study is far larger than any other optimum $\mathrm{N}$ density reported in the literature $(\sim 2$ at $\%$ at most). In other words, it became possible to achieve heavier $\mathrm{N}$ doping using urea without degrading the photocatalytic activity.

Fig. 8(b) shows the change in the degradation rate with the concentration of urea at the nitridation temperature of $550{ }^{\circ} \mathrm{C}$. The degradation rate has a maximum value with urea at 3 at $\% \mathrm{~N}$ although the effect of the concentration of urea upon the degradation rate is by far smaller than that of the nitridation temperature. In $\mathrm{N}-\mathrm{TiO}_{2}$ films, $\mathrm{N} / \mathrm{O}$ atomic ratio increases from 0.054 for B3-550 to 0.062 for B40-550. In contrast, the ratio of $\beta_{3}$ $\left(\mathrm{Ti}^{4+}\right)$ tends to decrease with the increase in urea concentration. However, the degrees of these changes are small, which results in a rather small effect of urea concentration on the degradation rate.

As indicated above, the optimum N/O ratio of $\sim 0.06$ for Btype powders is far higher than that of $\sim 0.01$ for A-type powders. Therefore, urea is shown to be superior to $\mathrm{NH}_{3}$ as a $\mathrm{N}$ source in photocatalytic activity under vis light irradiation. Table S1† shows the comparison of vis light photocatalytic activities in terms of degradation rate $\left(\mathrm{h}^{-1}\right)$ and quantum yield (\%) among various studies using $\mathrm{NH}_{3}$ gas for nitridation., ${ }^{\mathbf{5 1 1 5 6}}$ The present study gave the highest activity, demonstrating that urea is superior to mere $\mathrm{NH}_{3}$ gas. The optimum $\mathrm{N}$ density greatly depends on the density of defects. Taking the values revealed in Table 1 into account, the upper limit of the defect density for high activities is likely to be $\sim 0.5$ in terms of ratio of reduced $\mathrm{Ti}$ species $\left(\mathrm{Ti}^{3+}, \mathrm{Ti}^{2+}\right)$. When the defect density exceeds this limit, these defects greatly degrade the activities even though much $\mathrm{N}$ is incorporated in $\mathrm{TiO}_{2}$.

In the pioneering study performed by Asahi et al., it was suggested that $\mathrm{N}_{\mathrm{S}}$ is the origin of vis light activity of $\mathrm{N}-\mathrm{TiO}_{2} .{ }^{5} \mathrm{On}$ the other hand, the general agreement has been likely to be obtained among recent studies that $\mathrm{N}_{\mathrm{i}}$ is responsible for vis light activity rather than $\mathrm{N}_{\mathrm{s}}{ }^{\mathbf{1 0 , 1 2 , 1 3}}$ However, the present study implied that $\mathrm{N}_{\mathrm{S}}$ is still effective for vis light activities. Possibly, a lot of $\mathrm{V}_{\mathrm{O}}$ coexisted with $\mathrm{N}_{\mathrm{S}}$ in the $\mathrm{N}_{\mathrm{s}}$-dominant specimens of recent studies, which degrades photocatalytic activities. Although the production of a certain amount of $\mathrm{V}_{\mathrm{O}}$ is necessary for $\mathrm{N}$ doping into substitutional sites, the strict control of $\mathrm{V}_{\mathrm{O}}$ density is required for the achievement of high activity. In this respect, $\mathrm{NH}_{3}$ gas is hard to be controlled because of the abrupt increase in the reduction power above the onset temperature (i.e., $550{ }^{\circ} \mathrm{C}$ ). In contrast, urea can be more easily controlled since the reduction power gradually increases with the elevation of temperature.

It has been well known that the photocatalytic activity of $\mathrm{N}-\mathrm{TiO}_{2}$ under vis light irradiation is still lower than that of $\mathrm{TiO}_{2}$ under UV light irradiation., ${ }^{2,55}$ A major reason for it is shorter lifetimes of photoexcited carriers in $\mathrm{N}-\mathrm{TiO}_{2}$. $\mathrm{N}$-derived states were not 'hybridized' with $\mathrm{VB}$ of $\mathrm{TiO}_{2}$ but possibly 'localized' from it, as indicated in Section 3.3. A photoexcited hole has to move by hopping from one dopant $\mathrm{N}$ site to another many times to reach the photocatalyst surface. However, the average distance among neighboring dopant $\mathrm{N}$ sites is large due to small $\mathrm{N}$ density (as large as several \%). Accordingly, the probability of photoexcited holes to be recombined with electrons becomes fairly large, which results in short lifetimes of holes. Nevertheless, the reliable lifetimes of photoexcited carriers (in particular, holes) in $\mathrm{N}-\mathrm{TiO}_{2}$ have hardly been provided by any techniques so far. Our next attempt to measure carrier lifetimes in $\mathrm{N}-\mathrm{TiO}_{2}$ using TRPES is about to get underway.

\section{Conclusions}

The structural and electronic properties of $\mathrm{N}-\mathrm{TiO}_{2}$ thin films synthesized by sol-gel methods with or without urea and post calcination in $\mathrm{NH}_{3}$ gas were characterized by XRD and XPS utilizing synchrotron radiation. $\mathrm{N}-\mathrm{TiO}_{2}$ powders were also prepared for the estimation of visible light photocatalytic activities. $\mathrm{N}$-doped $\mathrm{TiO}_{2}$ thin films revealed polycrystalline anatase phases. $\mathrm{N}$ was shown to be chiefly doped into substitutional site. The VB structures of $\mathrm{N}-\mathrm{TiO}_{2}$ samples were composed of four bands similar to that of non-doped anatase $\mathrm{TiO}_{2}$. However, remarkable shoulder structures were recognized in VB XPS spectra for samples with high $\mathrm{N}$ densities. From these shoulder structures, localized states associated with doped $\mathrm{N}$ were successfully found at $0.24 \mathrm{eV}$ to $0.34 \mathrm{eV}$ above VBM in the band gap. This finding is roughly consistent with a lot of previous studies. Decomposition of $\mathrm{NH}_{3}$ took place at $550{ }^{\circ} \mathrm{C}$. Above this temperature, $\mathrm{N}$ incorporation and the reduction of $\mathrm{TiO}_{2}$ (i.e., the generation of oxygen vacancies and reduced $\mathrm{Ti}$ species) simultaneously occur by $\mathrm{NH}_{3}$. The former enhances photocatalytic activity, whereas the latter reduces it. In particular, the ratio of defect $\left(\mathrm{Ti}^{2+}\right.$ and $\left.\mathrm{Ti}^{3+}\right)$ density higher than $\sim 0.5$ greatly degrades vis light photocatalytic activity. It is difficult to achieve both high-density $\mathrm{N}$ and low-density defects using $\mathrm{NH}_{3}$ because of the abrupt increase in reduction power at $550{ }^{\circ} \mathrm{C}$. However, urea reduced the onset temperature of $\mathrm{N}$ incorporation to $500{ }^{\circ} \mathrm{C}$. Moreover, the increase in reduction power of urea was gradual at around $550{ }^{\circ} \mathrm{C}$. This enabled the synthesis of $\mathrm{N}-\mathrm{TiO}_{2}$ with high-density $\mathrm{N}$ and low-density defects by using urea at $550{ }^{\circ} \mathrm{C}$, giving the highest vis light photocatalytic activity. Consequently, the optimum $\mathrm{N} / \mathrm{O}$ atomic ratio was shown to be approximately 0.06 (corresponding to $\mathrm{N}$ density of 4 at\%). Namely, it became possible to achieve heavier $\mathrm{N}$ doping and better photocatalytic activity under vis light irradiation using urea than any other study only using $\mathrm{NH}_{3}$ gas for nitridation.

\section{Acknowledgements}

The XPS measurements were performed under the approval of the Photon Factory Advisory Committee (Proposal No. 2011G599). The authors thank Mr Taku Higuchi for his help in the XPS measurements.

\section{References}

1 A. Fujishima and K. Honda, Nature, 1972, 238, 37-38. 
2 (a) T. L. Thompson and T. Yates Jr, Chem. Rev., 2006, 106, 4428-4453; (b) S.-K. Lee, P. K. J. Robertson, A. Mills, D. McStay, N. Elliott and D. McPhail, Appl. Catal., B, 2003, 44, 173-184.

3 T. Okato, T. Sakano and M. Obara, Phys. Rev. B: Condens. Matter Mater. Phys., 2005, 72, 115124.

4 S. S. Soni, M. J. Henderson, J.-F. Bardeau and A. Gibaud, Adv. Mater., 2008, 20, 1493-1498.

5 R. Asahi, T. Morikawa, T. Ohwaki, K. Aoki and Y. Taga, Science, 2001, 293, 269-271.

6 Y. Nakano, T. Morikawa, T. Ohwaki, K. Aoki and Y. Taga, Appl. Phys. Lett., 2005, 86, 132104.

7 X. Chen, Y.-B. Lou, A. C. S. Samia, C. Burda and J. L. Gole, Adv. Funct. Mater., 2005, 15, 41-49.

8 R. G. Palgrave, D. J. Payne and R. G. Egdell, J. Mater. Chem., 2009, 19, 8418-8425.

9 T. Yoshida, S. Niimi, M. Yamamoto, T. Nomoto and S. Yagi, J. Colloid Interface Sci., 2015, 447, 278-281.

10 A. Kafizas, C. Crick and I. P. Parkin, J. Photochem. Photobiol., A, 2010, 216, 156-166.

11 O. Diwald, T. L. Thompson, T. Zubkov, E. G. Goralski, S. D. Walck and J. T. Yates Jr, J. Phys. Chem. B, 2004, 108, 6004-6008.

12 Z. Zhang, X. Wang, J. Long, Q. Gu, Z. Ding and X. Fu, J. Catal., 2010, 276, 201-214.

13 S. Sato, Chem. Phys. Lett., 1986, 123, 126-128.

14 H. Chen and J. A. Dawson, J. Phys. Chem. C, 2015, 119, 15890-15895.

15 I. Nakamura, N. Negishi, S. Kutsuna, T. Ihara, S. Sugihara and K. Takeuchi, J. Mol. Catal. A: Chem., 2000, 161, 205-212.

16 F. Dong, W. Zhao, Z. Wu and S. Guo, J. Hazard. Mater., 2009, 162, 763-770.

17 J. Zhao, E. G. Garza, K. Lam and C. M. Jones, Appl. Surf. Sci., 2000, 158, 246-251.

18 L. Mohapatra, K. Parida and M. Satpathy, J. Phys. Chem. C, 2012, 116, 13063-13070.

19 L. G. Devi and R. Kavitha, Appl. Catal., B, 2013, 140, 559-587.

20 A. L. Patterson, Phys. Rev., 1939, 56, 978-982.

21 M. Emori, M. Sugita, K. Ozawa and H. Sakama, Phys. Rev. B: Condens. Matter Mater. Phys., 2012, 85, 035129.

22 J. Wang, W. Zhu, Y. Zhang and S. Liu, J. Phys. Chem. B, 2007, 111, 1010-1014.

23 Y. Cong, J. Zhang, F. Chen and M. Anpo, J. Phys. Chem. C, 2007, 111, 6976-6982.

24 M. Sathish, B. Viswanathan, R. P. Viswanath and S. Gopinath, Chem. Mater., 2005, 17, 6349-6353.

25 X. Chen and C. Burda, J. Phys. Chem. B, 2004, 108, 1544615449.

26 (a) L. A. DeLouise and N. Winograd, Surf. Sci., 1985, 159, 199-213; (b) T. Jirsak, J. Dvorak and J. A. Rodgiguez, Surf. Sci., 1999, 436, L683-L690.

27 C. Feng, Y. Wang, Z. Jin, J. Zhang, S. Zhang, Z. Wu and Z. Zhang, New J. Chem., 2008, 32, 1038-1047.

28 C. D. Valentin, E. Finazzi, G. Pacchioni, A. Selloni, S. Livraghi, M. C. Paganini and E. Giamello, Chem. Phys., 2007, 339, 44-56.
29 A. V. Emeline, V. N. Kuznetsov, V. K. Rybchuk and N. Serpone, Int. J. Photoenergy, 2008, 2008, 258394.

30 J. L. Gole, J. D. Stout, C. Burda, Y. Lou and X. Chen, J. Phys. Chem. B, 2004, 108, 1230-1240.

31 F. E. Oropeza, J. Harmer, R. G. Egdell and R. G. Palgrave, Phys. Chem. Chem. Phys., 2010, 12, 960-969.

32 S. H. Cheung, P. Nachimuthu, M. H. Engelhard, M. K. Bowman and S. A. Chambers, Surf. Sci., 2007, 601, 1754-1762.

33 N. Saha and G. Tompkins, J. Appl. Phys., 1992, 72, 3072-3079.

34 Y. Zang, P. Xiao, X. Zhou, D. Liu, B. B. Garciaa and G. Cao, J. Mater. Chem., 2009, 19, 948-953.

35 E. Gyoegy, A. P. Pino, P. Serra and J. L. Morenza, Surf. Coat. Technol., 2003, 173, 265-270.

36 C. H. Shin, G. Bugli and G. D. Mariadassou, J. Solid State Chem., 1991, 95, 145-155.

37 M. Ceotto, L. L. Presti, G. Cappelletti, D. Meroni, F. Spadavecchia, R. Zecca, M. Leoni, P. Scardi, C. Bianchi and S. Ardizzone, J. Phys. Chem. C, 2012, 116, 1764-1771.

38 S. Livraghi, M. C. Paganini, E. Giamello, A. Selloni, C. D. Valentin and G. Pacchioni, J. Am. Chem. Soc., 2006, 128, 15666-15671.

39 C. D. Valentin and G. Pacchioni, Phys. Rev. Lett., 2006, 97, 166803.

40 S. Yin, K. Ihara, M. Komatsu, Q. Zhang, F. Saito, T. Kyotani and T. Sato, Solid State Commun., 2006, 137, 132-137.

41 Z. Wu, F. Dong, W. Zhao and S. Guo, J. Hazard. Mater., 2008, 157, 57-63.

42 A. K. Rumaiz, J. C. Woicik, E. Cockayne, H. Y. Lin, G. H. Jaffari and S. I. Shah, Appl. Phys. Lett., 2009, 95, 262111.

43 M. Batzill, E. H. Morales and U. Diebold, Phys. Rev. Lett., 2006, 96, 026103.

44 (a) Z. Zhang, S.-P. Jeng and V. E. Henrich, Phys. Rev. B: Condens. Matter Mater. Phys., 1991, 43, 12004-12011; (b) R. Asahi, Y. Taga, W. Mannstadt and A. J. Freeman, Phys. Rev. B: Condens. Matter Mater. Phys., 2000, 61, 7459-7465; (c) A. G. Thomas, et al., Phys. Rev. B: Condens. Matter Mater. Phys., 2007, 75, 035105.

45 M. Emori, A. Sakino, K. Ozawa and H. Sakama, Solid State Commun., 2014, 188, 15-18.

46 L. Mohapatra and K. M. Parida, Phys. Chem. Chem. Phys., 2014, 16, 16985-16996.

47 S. Nayak, L. Mohapatra and K. Parida, J. Mater. Chem. A, 2015, 3, 18622-18635.

48 K. Ozawa, M. Emori, S. Yamamoto, R. Yukawa, S. Yamamoto, R. Hobara, K. Fujikawa, H. Sakama and I. Matsuda, J. Phys. Chem. Lett., 2014, 5, 1953-1957.

49 K. Ozawa, S. Yamamoto, R. Yukawa, K. Akikubo, M. Emori, H. Sakama and I. Matsuda, Org. Electron., 2016, 31, 98-103.

50 S. Sakthivel, M. Janczarek and H. Kisch, J. Phys. Chem. B, 2004, 108, 19384-19387.

51 R. Nakamura, T. Tanaka and Y. Nakato, J. Phys. Chem. B, 2004, 108, 10617-10620.

52 H. Irie, Y. Watanabe and K. Hashimoto, J. Phys. Chem. B, 2003, 107, 5483-5486.

53 X. Cheng, X. Yu, Z. Xing and J. Wan, Energy Procedia, 2012, 16, 598-605. 
54 T. Lindgren, J. M. Mwabora, E. Avendaño, J. Jonsson, A. Hoel, C.-G. Granqvist and S.-E. Lindquist, J. Phys. Chem. B, 2003, 107, 5709-5716.

55 R. Q. Carbrera, C. S. Vazquez, J. A. Darr and I. P. Parkin, Appl. Catal., B, 2014, 160-161, 582-588.

56 X. Fang, Z. Zhang, Q. Chen, H. Ji and X. Gao, J. Solid State Chem., 2007, 180, 1325-1332.
57 E. A. Reyes-Garcia, Y. Sun, K. Reyes-Gil and D. Raftery, J. Phys. Chem. C, 2007, 111, 2738-2748.

58 F. Spadavecchia, G. Cappelletti, S. Ardizzone, M. Ceotto and L. Falciola, J. Phys. Chem. C, 2011, 115, 6381-6391.

59 H. Li, X. Li and Y. Huo, J. Phys. Chem. B, 2006, 110, 15591565. 